\title{
La preparación de la reforma en Galicia. Alonso Carrillo de Albornoz y la diócesis auriense en 1489
}

\author{
María Luz Ríos Rodríguez *
}

RESUMEN

En la primavera del año de 1489 el obispo de Catania, don Alonso Carrillo de Albornoz se establece en Santiago de Compostela. Llega como delegado del obispo de Avila, fray Hernando de

Talavera, quien junto con otros eclesásticos habia sido designado por Inocencio VIII - a instancias de los Reyes Católicos- para acometer la reforma eclesiástica en Galicia. Su

misión consiste en recabar una información fidedigna de la situación eclesiástica y por tanto también de uno de sus más graves problemas: las intromisiones de los laicos en los asuntos eclesiásticos. Un resultado directo de esta misión se conserva en el obispado de Ourense, al realizarse alli en ese mismo año de 1489, un "memorial, tumbo e inventario» que recoge diversa información sobre los beneficios y préstamos de toda la diócesis.

\section{ABSTRACT}

During the spring of 1489, the Bishop of Catania, don Alonso Carrillo de Albornoz settled down in Santiago de Compostela. He arrived as a delegate of the Bishop of Avila, fray Hernando de Talavera who, together with other ecclesiastics, had been appointed by the Pope Innocent VIIIth - by suggestion of the Catholic Kings - to develop the ecclesiastic reform in Galicia. His mission was to gather reliable information about the ecclesiastic situation and thus, about one of its most serious problems: the intromissions of the laymen in the ecclesiastics affairs. One of the direct results of that mission is preserved in the bishopric of Ourense, where during that year of 1489 , was written a «memorial, tumbo and inventory» with some information about benefices and «préstamos» of all the diocesis.

* Universidad de Santiago de Compostela. 
En la primavera del año de 1489 el obispo de Catania, don Alonso Carrillo de Albornoz se halla en Galicia ${ }^{1}$. Se establece en Santiago de Compostela dispuesto a cumplir una misión encomendada en último término por el pontífice Inocencio VIII, quien a instancias de los Reyes Católicos había promulgado dos bulas para la reforma eclesiástica en Galicia. El doble proyecto reformador de monarquía y papado, con intereses muchas veces contrapuestos, no impide una coincidencia básica: la necesidad de recabar una información lo más fidedigna posible de la situación eclesiástica gallega y de lo que parece uno de sus problemas fundamentales, las intromisiones de los nobles laicos gallegos en los asuntos eclesiásticos. Un resultado directo de esta misión de Alonso Carrillo se conserva en el obispado de Ourense, al realizarse allí en el mismo año de 1489 un «memorial, tumbo e inventario» que recoge diversa información sobre los beneficios y préstamos de toda la diócesis. En el memorial no va inserta la carta de comisión al obispo Alonso Carrillo, señalándose los motivos: «aqui no va ynserta por su gran prolesidad (sic)» y «porque ya es notorio en este Reyno de Galizya" ?

\section{SITUACIÓN ECLESIÁSTICA EN GALICIA Y MOTIVACIONES DE LA ELABORACIÓN DEL MEMORIAL.}

Las múltiples quejas de los eclesiásticos gallegos respecto a las intromisiones laicas se acrecientan desde finales del siglo XIV y a lo largo del siglo XV. El problema beneficial y el abuso de las encomiendas laicas sobre los monasterios había alcanzado en Galicia proporciones alarmantes. Ni los intentos reformadores de Juan I y su círculo de consejeros eclesiásticos prohibiendo las encomiendas, ni las bulas pontificias prohibiendo cualquier forma de enajenación de los bienes eclesiásticos habían obtenido resultado alguno en Galicia. Muchos de estos bienes eclesiásticos habían sido cedidos a nobles laicos de forma vitalicia a través de contratos prestimoniales y forales; a pesar de su condición vitalicia, estos laicos consiguieron renovaciones de estos contratos en cada nueva generación, de

\footnotetext{
1 Su llegada se produce tras la violenta pacificación de Galicia llevada a cabo por el gobernador Acuña, en un momento en que ejercía ya como nuevo gobernador Diego LóPEZ DE HARO y era alcalde mayor Sancho GARCIA DEL ESPINAR que como veremos estará presente en la catedral auriense cuando se publique solemnemente el edicto general.

2 Alonso CARRILLO DE Albornoz llega a Galicia por delegación del obispo de Avila, fray Hernando DE TALAVERA a quien Inocencio VIII había designado junto con el obispo de Ciudad Rodrigo y los arzobispos de Toledo y Sevilla para que se informasen detenidamente de la situación eclesiástica en Galicia.
} 
forma que en la práctica funcionaban como si fueran bienes transmisibles a los herederos y estuviesen incorporados al patrimonio familiar. En el pasado y en un momento de expansión socioeconómica, esta generalizada práctica prestimonial y foral había reportado indudables beneficios a laicos y eclesiásticos, pero ahora se había convertido en un problema acuciante ${ }^{3}$. Además esto había permitido a los nobles laicos erigirse «so color de encomienda y patronato", en defensores del patrimonio eclesiástico y les había permitido a través de derechos más o menos fundados o simplemente a través del ejercicio de la violencia, usurpar rentas eclesiásticas de todo tipo ${ }^{4}$.

Finalmente para acabar de complicar el problema acaba por aparecer una institución más sutil, con especial arraigo en Galicia, la de los clérigos "corozos» situados al frente de sus beneficios «encorozados". Estos clérigos ostentaban los títulos de unos beneficios, pero cedían a otros -eclesiásticos y laicos - el disfrute de sus rentas. La coroza es una capa de juncos secos o paja que se usaba para protegerse de la lluvia, de modo que los corozos eran las capas o los encubridores de los verdaderos disfrutadores del beneficio. No hace falta señalar el ínfimo nivel cultural y moral de estos eclesiásticos corozos. Por tanto el problema no era sólo atribuible a los nobles laicos sino también a los eclesiásticos: al bajo clero porque se prestaba iy qué remedio! a ejercer de «corozos"; al alto clero porque acaparaba un beneficio detrás de otro en el afán de obtener unas rentas que les permitieran mantener su elevado nivel de vida. Llamados a más altas misiones, no podían atender a todos estos beneficios por lo que utilizaban también clérigos corozos que se ocuparan de las «nimiedades» de la acción pastoral entre sus feligreses, de la atención al culto y de la conservación de las iglesias ${ }^{5}$.

3 Ríos Rodríguez, M.a Luz. As orixes do foro na Galicia medieval. Santiago 1993 y «Propiedad de la tierra y relaciones señoriales: el «praestimonium» en Galicia (1150-1300) en Señorío y Feudalismo en la Península Ibérica ss. XII-XIX. Zaragoza, 1993, vol III, pp. 197-207.

4 Debe tenerse presente la explosiva situación política que vive Galicia a partir de la década de los 60: la guerra irmandiña, la anarquía bajo el reinado de Enrique IV y firıalmente la guerra civil que implicarán a toda la sociedad gallega y por tanto también a muchos eclesiásticos que tomarán parte activa en estos conflictos.

5 El problema de los beneficios encorozados acabó por promover la llegada a Galicia de Fernando Basanta en 1464, enviado como nuncio de Pío II para ocuparse específicamente de los encorozamientos. FERNÁNDEZ ALONSO subraya el hecho de que se nombrase a un nuncio especial y el que además se fuese a ocupar «de manera prácticamente exclusiva « de los corozos, aunque su misión se saldó con nulos resultados. Basanta era gallego y por tanto buen conocedor del problema, pero también era arcediano de Abeancos (ob. de Lugo) desde antes de 1455, en 1456 obtiene el «perpetuo beneficio» de San Martín de Branio (arz. de Santiago), en 1457 estaba en Roma, ejerció como subcolector pontificio.... en fin que según FERNÁNDEZ ALONSO, «no sería extraño que también él redondeara sus legítimos ingresos, teniendo a su servicio alguno o algunos 
La violencia laica provoca en los eclesiásticos una multiplicación de las llamadas de auxilio desde mediados del siglo xv y se acude a la autoridad pontificia buscando un remedio más hipotético que real. El arzobispo compostelano don Alvaro de Isorna recurre al papa Eugenio IV detallando los abusos de los nobles laicos que se negaban a renunciar a los bienes eclesiásticos cedidos en préstamo por su predecesor don Lope de Mendoza. Como respuesta a don Alvaro de Isorna, la bula «Ad ecclesiarum praesertim» promulgada por Eugenio IV en 21 mayo 1445, hace referencia tan sólo al problema beneficial existente en la provincia eclesiástica compostelana, pero lo que allí se relata se puede extrapolar al resto de Galicia. A ella suceden una desconocida bula de Nicolás $\mathrm{V}$ a la que alude Pío II, la bula de Calixto III, «Ad reprimendas insolentias» de 4 de mayo de 1455 en la que -en frase de Fernández Alonso- se «ataca de raiz el problema fundamental de la violencia y la injusticia imperantes", y la específica intervención de Pío II que envía a Galicia a Fernando Basanta como nuncio pontificio en el año de 1464 con la orden de reprimir la práctica de los beneficios encorozados. Las bulas de Paulo II -bulas de 3 y 5 de enero de 1466 - y Sixto IV —-bula de 23 de julio de 1476 y 14 de julio de 1478continúan describiendo los múltiples atropellos y excesos que se cometen contra los eclesiásticos en Galicia, las usurpaciones de rentas, las conspiraciones contra el clero, continúan fulminando excomuniones y entrediches... Todo en vano ${ }^{6}$.

De modo que en la Asamblea Eclesiástica de Sevilla de 1478, el clero del reino pide a los Reyes Católicos que arbitren un remedio para la situación eclesiástica gallega. Se acude ahora también a la autoridad monárquica en busca de un remedio que es muy difícil de solucionar. Ni las actuaciones de todos los pontífices de la segunda mitad del siglo $\mathrm{xV}$ - a las que acabamos de citar se sumarán las de Inocencio VIII y las de Alejandro VI- ni las de los Reyes Católicos conseguirán resolver un problema tan complejo ${ }^{7}$. Aunque es indudable que a finales del siglo $\mathrm{xV}$, se

sacerdores «corozos". Una vez más lá solemne intervención pontificia había sido totalmente ineficaz". FERNÁNDEZ Al.onso, J. "Los beneficios encorozados de Galicia en el siglo XV. Fernando Basanta, nuncio de Pio II (1464)», Anthologica Annua 28-29 (1981-1982), pp. 553-579.

6 Fernández Alonso, J. Op. cit. p. 558. Más amplia descripción de la situación en la sede compostelana y el resto de Galicia en GARCIA ORO, J. Cisneros y la reforma del clero español en tiempo de los Reyes Católicos. Madrid, 1971 y del mismo autor, Galícia en los siglos XIV y XV, 2 T. A Coruña, 1987. Vid. también la clásica obra de LÓpEZ FERREIRO, A. Galicia en el último tercio del siglo XV, (1. ${ }^{\mathrm{a}}$ ed. Santiago, 1883), 3. ${ }^{\mathrm{a}}$ ed. corr. y ampliada por FERNÁNDEZ-POUSA, R. Vigo 1968.

7 Para un planteamiento más amplio de la reforma vid. NiEto SoRIA, J. M. Iglesia y génesis del estado moderno en Castilla (1369-1480). Madrid, 1994 y las obras de AzCONA, TARSICIO DE, Isabel la Católica. Estudio crítico de su vida y su reinado. Madrid, 1993 ( $3 .^{2}$ de. react.) y La elección y reforma del episcopado español en tiempos de los Reyes Católicos. Madrid, 1960. 
La preparación de la reforma en Galicia. Alonso Carrillo de Albornoz y ...

consiguió poner coto a las violencias nobiliarias laicas que a partir de este momento, tratarán de defender sus derechos más por la vía jurídica que por la fuerza de las armas.

Pontífices y monarquía parecen estar de acuerdo respecto a que la reforma de las instituciones eclesiásticas - seculares y regulares- debía fundamentarse en primer lugar en liberarse de la tutela laica; los otros múltiples aspectos de la reforma se acometerian mejor si se solventaba o se ponía coto a éste en primer lugar. La coincidencia de intereses en este punto entre papado y monarquía suponía que el restablecimiento del orden y la justicia pasaba por someter a una nobleza laica que no sólo imponía exacciones injustas sobre iglesias y monasterios, sino que también se adueñaba de las sedes episcopales encarcelando a sus obispos, o se pertrechaba dentro de las catedrales-fortaleza en el afán de imponerse sobre sus enemigos. A la monarquía le convenía controlar las fortalezas y castillos de los nobles laicos, pero también era esencial el control de las fortalezas episcopales con sus ciudades ${ }^{8}$.

Podemos considerar como antecedentes immediatos a la elaboración del memorial auriense que nos ocupa el viaje a Galicia que en 1486 realizan los Reyes Católicos a Galicia, en donde conocen de primera mano las quejas de los eclesiásticos y se publican disposiciones particulares y generales para todo el reino de Galicia, en las que se commina a los nobles laicos a renunciar a sus encomiendas sobre cualquier tipo de bienes eclesiásticos.

A renglón seguido se solicita la autorización de la Santa Sede para acometer la reforma; la embajada de Bernardino de Carvajal en Roma obtiene de Inocencio VIII la bula «Inter curas multiplices» - de 27 diciembre 1487- expresamente dedicada a los beneficios ocupados por laicos y a los beneficios encorozados. Aquí se encarga una exhaustiva investigación sobre los beneficios gallegos y sobre quién los ocupa; los que estuviesen ocupados por laicos, los que contasen con el encubrimiento de clérigos corozos deberían ser devueltos a la Iglesia bajo penas gravísimas. Además

\footnotetext{
8 Pueden aducirse ejemplos de estas violencias de la nobleza laica en todas las diócesis gallegas. En Ourense tuvo especial relevancia la guerra que enfrentó en 1471-72 al conde de Benavente don Rodrigo Alonso Pimentel, con el conde de Lemos don Pedro Alvarez Osorio quien se habia fortificado dentro de la catedral con miembros del cabildo y del concejo. Los destrozos causados son pormenorizadamente descritos por el canónigo y procurador del cabildo Juan de Loureiro en 1480, ya que en esa fecha todavía están sin reparar los daños en la fachada norte y en las capillas de S. Juan y del Crucifijo. El de Benavente no aportará fondos para sufragar los gastos hasta 1498 y el de Lemos lo hará todavía más tarde. Ríos Rodríguez, M. ${ }^{2}$ Luz, «Capillas y capellanías en la ciudad de Ourense según el memorial-tumbo de 1489". En prensa en "Homenaxe a X. M. Pose Antelo. In Memorian". Univ. de Santiago de Compostela.
} 
los comisionados para tal investigación tienen facultad para establecer una nueva organización beneficial en Galicia ${ }^{9}$. Esta es pues la misión encargada a Alonso Carrillo de Albornoz y las motivaciones que explican la elaboración del memorial-tumbo de Ourense en 1489.

\section{LA DIÓCESIS DE OURENSE Y EL MEMORIAL-TUMBO DE 1489.}

El titular de la sede episcopal auriense era desde comienzos de 1486 , el obispo de Ventimiglia, D. Antonio Palavicino Gentili que nunca llegó a ocupar su diócesis, aunque retuvo al obispado hasta su muerte en 1507; ejercía el cargo de datario en la Curia romana y en 1489 se convertía en "cardenal de Sta Anastasia», título con el que es designado en el memorial ourensano ${ }^{10}$. El nombramiento de Gentili para la sede auriense, un obispo "no natural» del reino, se llevó a acabo tras un tira y afloja entre papado y monarquía. En las instrucciones de los reyes al conde de Tendilla para la embajada en Roma, se acepta que Gentili sea promovido a la sede auriense, siempre que su actual obispo Diego de Fonseca pase a ocupar la sede vacante de Coria y siempre que Gentili deje la abadía de Foncea para don Juan de Ortega. Los reyes recuerdan que ya había sido hecha la súplica para que la provisión de Coria recayese en don Diego de Fonseca e insisten en dos de los caballos de batalla del proyecto reformador monárquico: la residencia del obispo en su sede y que éste sea natural del reino, aspectos en los que los monarcas pueden transigir en función de mayores intereses ${ }^{11}$.

9 GARCIA ORO, J. Cisneros...., p. 74.

10 Su predecesor fue don Diego DE FONSECA, ocupando esta diócesis desde el 28 de febrero de 1470. D. Antonio Palavicino GentILI, obispo de Ventimiglia, fué promovido a la sede auriense el 27 de enero de 1486 y creado cardenal el 9 de marzo de 1489; su muerte acaeció el 2 de setiembre de 1507. Marín, T. y AldEA, Q. (Dirs). Diccionario de Historia Eclesiástica de España, Madrid, 1972-1986, voz "Orense", p. 1834.

11 Con fecha de 20 de enero de 1486 , se recoge en la instrucción $n .^{\circ} 3$, todo lo relativo a don Diego DE FONSECA: «... Su Santidad tenia deliberado de haser esta provision desta dicha yglesia de Coria en persona del dicho don Diego DE FONSECA, obispo de Orense, después...la difirió y nos escribió por su breve encargándonos que diesemos nuestro voto e consentimiento para que esta yglesia oviese el obispo de Veyntimilia, su datario. A lo qual nos ovimos repondido que bien nos pluguiera de hazer lo que Su Santidad nos enbiava rogar pero que esto no avia lugar asi porque esta yglesia requiere la presençia del perlado tanto y más que otra de nuestros reynos... «. En la instrucción $n .^{\circ} 4$, se recoge todo lo relativo a don Antonio GENTILI: «... enbiamos saber a Su Santidad que nos seriamos contentos proveyendo Su Santidad del obispado de Coria al dicho obispo de Orense, proveyese del obispado de Orense a quien Su Santidad ploguiese con tanto que fuese nuestro natural y que avriamos mucho plazer que fuese el obispo de Veyntemilia, su datario, porque es persona açebta a Su Santidad y de quien nos podriamos ser servidos, dexando el la abadia de Fonçea para don Juan DE ORTEGA, provisor de Villafranca....». En el complemento a. 
La preparación de la reforma en Galicia. Alonso Carrillo de Albornoz y'...

2.1. La fuente: el «memorial tunvo e ynventario e información de los tytolos de las parrochias yglesias e de los veneficios e prestamos symples e servyderos de todo el obispado e diocesis dOurense".

En el año de 1913, Cándido Cid comenzó una publicación que bajo el título de "Una visita pastoral de la diócesis Auriense en 1487" extractaba algunos aspectos que consideraba más dignos de atención de ese «libro de visitas» del Archivo de la Catedral. En su relación recoge algunos de los ornamentos de las capillas de la catedral y de las iglesias parroquiales - calices de plata o plomo- algunos libros o su falta -misales, manuales, salterios, etc-, algunos de sus bienes immuebles y el número de feligreses - vecinos según Cid- con que contaba cada parroquia; pero sobre todo presta especial atención a quienes figuran como patronos eclesiásticos y laicos de las parroquias y qué rentas detraían de cada una de ellas. Según manifiesta en la introducción, la rapacidad de los señores contra las iglesias sumía en un estado de pobreza a los templos aldeanos que aparecen despoblados de feligreses. La nómina de "depredadores" de las parroquias abarca a los Condes de Monterrey, Ribadavia, Lemos y Benavente y a otro amplio conjunto de hidalgos, escuderos, señores (y señoras) de la diócesis auriense ${ }^{12}$.

Mi interés por conocer de primera mano esta visita de 1487 me condujo al Archivo de la Catedral de Ourense ${ }^{13}$. No existía tal libro de visitas, pero sí un memorial e inventario de dichas parroquias, realizado en el año de 1489 y que se correspondía con el extracto de los asuntos que le habían interesado a $\mathrm{C}$. Cid y que presentaba una gran amplitud. El indudable valor e interés de tal memorial no pasó desapercibido para E. Duro Peña que realizó una completa transcripción de lo que tituló «Tumbo de Beneficios del Obispado de Orense (1489)", trabajo que por desgracia todavía permanece inédito, aunque se espera una pronta publicación ${ }^{14}$.

\footnotetext{
las instrucciones en donde se precisan los puntos en los que puede o no ceder, se insiste en que en ningún caso debe hacerlo para la provisión de Coria a don Diego DE FONSECA y respecto a la provisión del obispado de Orense se dice que « consentyreys en ella tanto quel abadia de Fonçea se provea al provisor y no en otra manera». SÚAREZ FERNÁNDEZ, L. Política internacional de Isabel la Católica. Valladolid, 1996. T.II, p. pp.341-343 (Doc. n. ${ }^{\circ} 78$ ) y pp. 361 (Doc. n. ${ }^{\circ} 79$ ).

12 CID, Cándido, «Una visita pastoral de la diócesis auriense en 1487", Boletín de la Comisión Provincial de Monumentos Históricos y Artísticos de Orense, V (1913-1918) y VI (1918-1922).

13 En el marco del Proyecto de investigación «La organización parroquial en Galicia (siglos VIXVI) financiado por la Dirección General de Investigación Científica y Técnica (PS95-0099).

14 Archivo Catedral Ourense. Sección C- N. ${ }^{\circ}$ 30. El actual Archivero de la Catedral M. A. GONZÁLEZ GARCíA, tuvo la gentileza de pertimirme utilizar ese material inédito mientras estaba gestionando su posible publicación por el Consello da Cultura Galega, por lo que quiero expresarle aquí mi agradecimiento.
} 
Al analizar la información aportada por el tumbo se observa efectivamente que no responde a una visita pastoral. Si así fuera sería la primera de las visitas medievales conservadas en Galicia, pero en la fuente faltan buena parte de los elementos consustanciales a una visita. Sin embargo la confusión procede también del folio introductorio a la composición del libro becerro realizada en 1566; en este folio de habla también del «libro que contiene una visita general y aberiguación de los beneficios desta diócesis que encomiença por la cathedral... y especifica las parrochiales que se bisitaron cuya presentaçion son y los cargos y tributos que pagan a los berdaderos patronos y mas personas... el qual fue fecho por la buena memoria de Juan de Deza.... y no se acabó por no se aber presentado todas las parrochiales. Las que se presentaron dixeron y se da credito a sus dichos y se juzga y executa lo en el contenido y es llamado bezerro».

\subsection{Los prolegómenos: Carta de comisión de Carrillo de Albornoz a Juan de Deza y publicación del Edicto general.}

El memorial se inicia con una carta de comisión otorgada por D. Alonso Carrillo de Albornoz, obispo de Catania, juez apostolico subdelegado «por virtud de la abtoridad apostolica a el dada e conçesa por el nuestro muy santo padre Ynoçencio papa Otabo" y miembro «del Consejo del Rey e de la Reyna nuestros señores"; la suscribe en Santiago el día de Corpus Christi - que cayó en 19 de junio-y la dirige al provisor y vicario general de la iglesia de Ourense, D. Juan de Deza, arcediano de Buval, en ausencia del obispo de la sede, D. Antonioto Gentili. Será pues su provisor D. Juan de Deza, el que se ocupe directamente de recabar toda la información de la diócesis que contiene el memorial, tras proclamar solemnemente el edicto general en la catedral ourensana.

En la carta de comisión D. Alonso Carrillo de Albornoz alude a una carta enviada por $\mathrm{D}$. Juan de Deza, de la que se infiere la proclamación del edicto previo - Carrillo habla de la diligencia mostrada por el provisor "en la afixion de la carta de hedito»- que convocaba a todos los clérigos ourensanos a presentarse con sus títulos en la ciudad de Santiago. En la carta Juan de Deza debe señalar que el «negoçio es de tal calidad que deve ser favoresçido por todos los que tienen buen zelo, mayormente por los eclesyasticos a quien principalmente toca» ya que Carrillo se muestra completamente de acuerdo; pero además Carrillo repite el argumento utilizado por Juan de Deza en su carta según el cual "en esa diocesis ay pocos benefiçios en que se puedan los clerigos manthener e por su pobreza resçeberian grande fatiga en venir a presentar sus titolos y por esto 
queriades que lo cometiesemos en esa dioçesis». En resumen, aunque Carrillo considera que en ningún sitio se podía hacer tan bien como en Santiago «por muchas cabsas que non conviene escrivir», confiando en la experiencia y diligencia de Juan de Deza y en que está seguro de que mirará por su honra, le confiere el poder necesario para que toda la información se obtenga —en el tiempo y forma convenidos- en la propia diócesis auriense, aunque "aca non falta quien diga que se puede mucho encobrir».

Con la carta de Carrillo en su poder, Juan de Deza puede proclamar públicamente el edicto general en la procesión solemne que el domingo 21 de junio se celebró en la iglesia catedral del señor S. Martiño de la ciudad de Ourense. El edicto fue leído y publicado en "alta e inteligible" voz por el racionero Roy Vázquez por mandato del provisor, estando presentes "por testigos» las dignidades, canónigos y beneficiados de la dicha iglesia, el doctor Sancho Garcia del Espinar "del Consejo del Rey e de la Reyna nuestros señores e su alcalde mayor en este Reyno de Galizya", los regidores de la ciudad ourensana y otros vecinos y moradores en dicha ciudad, incluyendo el notario que da fe de la publicación.

\subsection{Los afectados y el objetivo o «negocio».}

Dirigido en primer lugar a todas las dignidades, canónigos y racioneros de la iglesia catedral de S. Martiño de Ourense. Las dignidades citadas por sus nombres en el edicto son el deán, chantre, arcedianos de Castela, Baroncelle, Celanova y Limia y maestrescuela de la iglesia de Ourense; a esta relación hay que añadirle el arcediano de Buval que como hemos señalado, era el provisor Juan de Deza y el abad de la Trinidad que era también dignidad de la catedral desde el obispado de García Manrique (13681376) ${ }^{15}$.

Tras las dignidades, está dirigido a los canónigos de la catedral —en número de 18-, los racioneros -en número de 10-, el dobleiro

15 El deán era D. Pedro de Herrera; D. Pedro de Tamayo, chantre; D. Rodrigo Pacheco - hermano del marqués de Villena- arcediano de Castela; D. Benito DE CHABAS, arcediano de Varoncelle; Frey Lope DE RIBADAl, abad de Celanova y arcediano de Celanova; D. Gonzalo DE VILAIOHAN, arcediano de Limia; D. Nuño AlvaRez dE Guití́n, maestrescuela. El abad de la Trinidad, D. Rodrigo PIMENTEL, hijo del «magnifico señor conde de Benavente», disfrutaba de su abadía desde el Estudio General de París del reino de Francia, según consta en este memorial-tumbo. Para las dignidades de la catedral ourensana vid. DURO PEÑA, E. «Las antiguas dignidades de la catedral de Orense», Anuario de Estudios Medievales, Barcelona, 1964. 
-Fernando Alonso do Campo- y por último dirigido también a todos los "clérigos, curas e retores" de todo el obispado de Ourense que posean en cualquier manera "benefiçios atitulados curados e symples e servideros".

Todos estos afectados que debían comparecer personalmente con sus títulos en la ciudad de Santiago y ante dicho señor obispo, el cual «acatando a la calidad del tiempo e a la fraxilidad e thenuidad e ynpotençia de algunas personas eclesyastycas e a la distancia del camino, movido de venidad (sic) e queriendo usar de ella con vos las sobredichas dignidades e clerezia de todo el dicho obispado", le envía el poder al provisor Juan de Deza para que pueda tenar plena información de todo lo ordenado y pueda recibir la copia de los titulos de los beneficios curados, simples y servideros, para que le sea remitida a Carrillo, la relación de las "provisiones, titolos e encoroçamientos, feudos e enajenamientos desta dicha yglesia catedral e de las parrochias e simples» del obispado.

Por tanto todos y cada uno de los afectados «syngulariter e syngulis» tendrán que comparecer personalmente en la ciudad de Ourense ante el provisor del obispo, Juan de Deza, para presentar los títulos de sus beneficios y parroquias y declarar « e dar por recuento e memorial los fueros e feudos de los dichos vuestros venefiçios e declarar las personas que los poseen e tienen». E insiste en que asimismo las dignidades deben cada una de ellas decir y declarar los beneficios y parroquias curadas y los simples y servideros «que están encoroçados e que comen e esfrutan las personas seculares en vuestra juridiçion e dignidades».

\subsection{El plazo y sus prórrogas.}

El obispo D. Alonso Carrillo de Albornoz había concedido de plazo para presentarse ante él en Santiago «fasta diez dias del mes de julio proximo venidero del año presente de ochenta e nueve años». Ahora Juan de Deza ordena que desde el momento en que sea leída y publicada en la catedral ante notario y testigos, todos los afectados tendrán de plazo «fasta doze dias primeros syguientes ynclusyve", es decir un plazo muy corto. Dado que la publicación tuvo lugar el domingo 21 de junio en la procesión solemne realizada en la catedral, el plazo concluía el dia 2 de julio que caía en dia de quinta feira, esto es, jueves. De esta forma, el provisor tendría todavía unos días para remitir toda la información a Santiago. Sin embargo Juan de Deza el dia uno de julio, víspera del dia de cumplimiento del plazo se ve obligado a prorrogarlo «fasta dia martes syguiente que seran sete dias andados deste presente mes de julio". La razón de la prórroga se fundamentaba en que dada la comminatoriedad del asunto al estar los 
afectados obligados «en virtud de santa ovediençia e so pena descomunion", podían incurrir en dichas censuras eclesiásticas y algunos clérigos no habían podido presentarse ante el provisor en un término tan perentorio. De hecho D. Alonso Carrillo de Albornoz, «usando de veninidad» ampliará nuevamente el plazo concedido a la diócesis de Ourense hasta el 20 de julio debido a «algunos ympedimentos que nos han sydo expuestos e declarados». La carta esta fechada en la ciudad de Santiago, el día seis de julio y ya no habrá ninguna nueva prórroga.

\section{LA CATEDRAL Y LAS IGLESIAS DE LA CIUDAD DE OURENSE. LAS IGLESIAS PARROQUIALES DE LA DIÓCESIS.}

Tras estos folios introductorios, se recogen a continuación los nombres, títulos, rentas y derechos en general de las dignidades de la catedral -Deán, Chantre, Arcedianos de Limia, Bubal y Castela, Abad de la Trinidad-, los títulos de las canonjías, racioneros y dobleiro. Y finalmente se enumeran nombres, títulos, rentas, heredamientos, ornamentos y libros de las diversas capillas de la catedral con sus respectivos capellanes. Canónigos, racioneiros y dobleiro, presentan sus títulos sin que exista ninguna precisión más sobre las rentas que perciben.

Las dignidades después de presentar sus títulos fidedignos juran en pública forma el número de iglesias parroquiales que pertenecen a tal dignidad, así como, en principio, los derechos y rentas que perciben por ellos. Pero de hecho son contados los que hacen tal declaración, de modo que hay que acudir a la detallada descripción de cada una de las iglesias parroquiales encuadradas en sus respectivos marcos, para conocer lo que pagan por procuraciones a cada una de estas dignidades ${ }^{16}$.

En el arcedianato de Limia existen sesenta iglesias parroquiales «de vysitaçión e de pilas e algunas delas que tenían algunos anexos». Entre sus derechos figuran la provisión de todos los beneficios vacantes y percibir las procuraciones y colaciones y las luctuosas de los clérigos que fallecían. Sin embargo el arcediano de Limia, D. Gonzalo de Villajuan, no hace constar lo que «rentaban las dichas yglesias del dicho su arçedianazgo de procuraçiones en cada un anno"(está en blanco en el memorial).

\footnotetext{
16 Ese pago en moneda por las procuraciones es el único cuantificable ya que es imposible hacerlo respecto a las percepciones de los diezmos en pan y vino de los «dextros» y de las «searas» de las iglesias, así como por otros cobros a los que aluden en ocasiones.
} 
En la Chantría existen veintisiete iglesias parroquiales «que teen pilas de boutyzar e algunas teen alguus anexos". Tiene los mismos derechos que el arcediano de Limia y declara que percibe los diezmos de pan y vino de los dextros y searas de dichas iglesias y de sus anexos. Además su dignidad renta «poco mas o menos cada un anno de treze fasta quinze mill mrs. de brancas» ${ }^{17}$.

En el Arcedianato de Buval existen cincuenta y cinco o cincuenta y seis iglesias parroquiales y algunas anexas a otras «por seren pobres». Tiene los mismos derechos que los anteriores y además lleva «as chançelarias das colaçios». Tampoco declara lo que rentan en procuraciones cada año en pan y vino y dineros (está en blanco en el memorial).

La abadía de la Trinidad declara a través del capellán del señor abad don Rodrigo Pemintel, una renta de sesenta mil «mrs. de brancas», señalando también los tributos que tenía que pagar.

En el Arcedianato de Castela no se declaran ni el número de parroquias ni lo que rentan; tampoco se presenta título alguno ya que el regidor de la ciudad de Ourense, Vasco Blanco se presenta "en nome de don Rodrigo Pacheco, hermano del señor marqués de Villena, arçediano de Castela ena yglesia dOurense" y señala que dicho señor "estaba en la guerra de los moros en serviçio de sus Altezas" y que por ello no podía presentarse con su título aunque se dice «que fora del provido por virtud de un yndulto apostolico a el conçeso».

Como puede apreciarse en estos primeros folios del memorial que recogen las «dignidades, calongias e raçiones del cuerpo de la iglesia cathedral»" (fols. $2 \mathrm{v}-12 \mathrm{v}$ ), se presta escasa o nula atención a las rentas y derechos de estos eclesiásticos y se pone el acento sobre todo en sus títulos, quien los emitió y dónde, fecha, firma y sello de la autoridad eclesiástica y del notario correspondiente, etc. Es evidente que una parte importante de la información y que además se esperaba obtener, pues de lo contrario no hubieran existido esos espacios en blanco en el memorial, le estaba siendo sustraída a don Alonso Carrillo de Albornoz. Si esto sucedía en la misma catedral es factible pensar que los clérigos de las parroquias podían hacer otro tanto.

\footnotetext{
17 En esta renta va comprendida la cuarta parte del prestamo de las Quartelas Mayores y el tercio del prestamo de las Quartelas Menores que son anexas a la Chantria «e estan e consiysten enos diezmos da çibdad dOurense". Más adelante señala que el cuerpo de la dignidad sin los dichos prestamos, renta cada un año setenta y ocho fanegas de pan, poco más o menos, y cuatro o cinco moyos de vino y dos mil pares de blancas de procuraciones.
} 
El grueso de la información del memorial corresponde a la descripción de las iglesias parroquiales, encuadradas en sus respectivos marcos y por este orden: Deanato, Arcedianato de Castela, Arcedianato de Baroncelle, Chantría o Chantrádigo, Arcedianato de Bubal, Maestrescolado de Caldelas, Maestrescolado de Orcellón, Arcedianato de Celanova y Vicariato.

En cada una de estas iglesias se recoge una abundante información: advocación y denominación de la iglesia, si es o no parroquial, si es o no anexa, quién es su clérigo, a quién pertenece el derecho de presentación y colación que otorga el título correspondiente y si es fidedigno o no. Qué cargos $u$ obligaciones tienen y si deben pagar algún tributo y a quién. Ornamentos y libros señalando algunos de los clérigos no sólo lo que hay, sino también lo que falta. A continuación se recogen los foros y heredamientos de estas iglesias y las rentas que obtienen o deberían obtener por ellas. Y finalmente se declara el número de feligreses pertenecientes a cada parroquia y su rendimiento global, ambos con carácter aproximativo pues se dice siempre que "serán poco más o menos..." En algunos casos también se señalan las singularidades de cada una de ellas: bulas de dispensación «a duo incompatibilia» para aquéllos clérigos que disfrutan de más de un beneficio; dispensas apostólicas para poder recibir las sagradas órdenes en el caso de los clérigos bastardos, etc.

\section{CONCLUSIONES.}

En el memorial-tumbo de la diócesis ourensana son multitud el número de laicos - grandes nobles, pero también escuderos y señoresque detraen rentas de las iglesias parroquiales, fundamentados unos en derechos de patronato y otros de manera injusta y arbitraria. A algunos de estos últimos son a los que aluden ciertos clérigos cuando declaran que « de dos o tres años a esta parte y con favor de la justicia real» han dejado de pagar esos tributos ${ }^{18}$. Sin embargo en el memorial son muy escasos los clérigos que abiertamente se declaran corozos y que aseguran que de

18 «...que lle soya de levar cada ano de ynposiçion e por força contra sua voontade el conde de Ribadavia duas fanegas de pan e trynta mrs. vellos por touçino, e que el dese dous anos a esta parte con favor de la justiçia del rey e reyna nuestros señores non llas quiso pagar» (S. Cristobo DE AMIUDAL, arcedianato de Castela). Aunque sin duda son también abundantes las imposiciones arbitrarias: «...que pagaba mas ao conde de ynposiçion en cada un ano trynta mrs. vellos; que Ile leva de ynposiçion en cada un ano contra sua vontade Gonçalo FERNÁNDEZ DE VILARINo seys mrs. vellos, e outros seys mrs. Pedro Ougea dALvan en cada un ano" (Sta M. a DE FreAs, arcedianato de Castela). 
ahora en adelante serán ellos mismos los que «coman y disfruten sus beneficios» ${ }^{19}$. Las terribles penas espirituales en las que podían incurrir no debían de ser suficientes para cambiar un modo de vida al que ya se habían acomodado. En el memorial se constata también que junto con los seculares hay muchos eclesiásticos - monasterios, abadías y órdenes militares de la diócesis auriense y de fuera de ella- que disfrutan de una buena parte de las rentas de estas iglesias parroquiales y así continuarán haciéndolo en el futuro. Una detracción de rentas tanto más grave cuanto que se realiza sobre unas iglesias parroquiales que nacieron vinculadas a la dispersión de los núcleos de poblamiento gallegos y que en muchos de los casos, al contar con un escaso número de feligreses, eran inevitablemente pobres.

También llama la atención la relativa abundancia de bulas de dispensación de incompatibilidad de beneficios curados; aun argumentando la exigüidad de muchos de ellos, es evidente que la Curia actúa por un lado de forma contraria a lo que trata de emmendar por el otro. Esa pobreza de las iglesias parroquiales que destaca el propio provisor Juan de Deza, explicaría más las bulas de anexión que estas otras de dispensación "a duo incompatibilia" aunque sean sólo durante la vida del beneficiario. Las bulas de anexión son también relativamente abundantes y es necesario destacar que el memorial se muestra contundente en caso de que no se presenten los correspondientes títulos fidedignos. Tal parece que en este punto no están dispuestos a transigir. En cierta manera el memorial también refleja las contradicciones de la Curia y de la propia Iglesia Auriense, así como los conflictos existentes entre Curia y Monarquía: un obispo no residente y no natural del reino, un alto clero catedralicio que solicita la intervención monárquica pero que se resiste a ella en cuanto llega y un clero parroquial que se halla en una situación muy diversa: algunos clérigos parecen contar con recursos suficientes dada la renta que declaran obtener; otros, los corozos, no pueden disfrutar de su beneficio y están completamente a expensas de lo que les suministre el verdadero beneficiario de su iglesia.

La labor de Alonso Carrillo de Albornoz y por su mandado, de Juan de Deza consistió en recabar primero toda la información necesaria para, una vez conocida y sopesada, dar el siguiente paso, acometer la reforma del

\footnotetext{
18 «... e diso que tinna o dito benefiçio en titulo e que o arrendara o anno pasado a Alfonso CaLvo DE BANGA que o collera por el en seu nome por arrendamento. e que en adiante que o entendia de comer sy llo non comesen por força; e que non daba nin entendia de dar ymposyçion nin dadiba do dito benefiçio por modo de coroça a persona algua..." (Sta M. ${ }^{a}$ DE AMARANTE, arcedianato de Castela).
} 
clero secular en Galicia. La diócesis auriense parecia ser un buen espacio de pueba, dada la no residencia de su obispo e incluso el hecho de que no fuese natural del reino, ya que ello podía en cierta manera facilitar la labor investigadora del comisionado. El resultado es desigual: por una parte la información obtenida sobre las iglesias parroquiales parece ser bastante fiable a excepción del ya comentado escaso número de clérigos que se reconocen "corozos»; por otra parte, las dignidades y demás miembros de la catedral ourensana, se resisten a declarar el monto de sus rentas. Ello confirma que lo que interesaba al comisionado por encima de todo, era asegurarse la fiabilidad de los títulos del alto y bajo clero y conocer los patronos o derechos de presentación de los laicos y eclesiásticos sobre las iglesias parroquiales junto con los tributos que por ello pagaban.

Cuando en 1493 el que fuera gobernador de Galicia don Diego López de Haro, sea enviado a Roma como embajador por los Reyes Católicos llevando sus instrucciones ante el nuevo papa Alejandro VI, el problema eclesiástico de Galicia se planteará en términos jurídicos y por esta vía seguirá en el futuro. Por un lado se recogen las alegaciones de los «que han llevado e llevan los dichos frutos e rentas de las dichas yglesias... de mas de quarenta años a esta parte" ya sean eclesiásticos o laicos y alegando sus diversas razones; por otro lado se recogen las alegaciones «por parte de los perlados, curas e clérigos de las dichas iglesias» que dicen lo contrario de los primeros. La conclusión es obvia: "lo qual todo visto ha paresçido la cosa ser dificultosa en fecho e en derecho". En ellas se alude a como el papa Inocencio VIII hizo cargo del asunto al obispo de Avila "que por entonces hera, que agora es arçobispo de Granada" y todo lo que se contenía en sus bulas apostólicas.

En esas instrucciones se refiere como «el obispo de Catania como subdelegado del dicho obispo de Avila fue a entender en la dicha reformaçion, e por la ynformaçion que sobre ello ha avido paresçe que segund la dificultad e diversydad de los casos e cabsas por donde se llevan los frutos e renta de las dichas yglesias, asy deçimales como non deçimales, non se podría fazer la dicha reformaçion como se deve syn nueva provision de Su S...." ${ }^{20}$. En 1493 los Reyes Católicos solicitan otra nueva provisión, otros nuevos comisionados. Al menos el obispo de Catania, Alonso Carrillo de Albornoz - quien como se sabe continuará en el futuro ocupándose de la reforma eclesiástica - realizó una minuciosa labor informativa que promovió en la diócesis auriense la elaboración del memorial-tumbo de 1489.

20 Vid. la publicación del texto en GARCIA ORO, J. Cisneros... pp. 74-77 y más completo todavía en FERnÁNDEZ Alonso, Op. cit. p. $577-579$ (doc. n. ${ }^{\circ} 4$ ). 